\title{
Gravity data requirements for decimetre accuracy regional geoid using Stokes' Remove Compute Restore technique in Nigeria
}

\author{
Joseph Olayemi ODUMOSU ${ }^{1, *} \mathbb{D}$, Victor Chukwuemeka NNAM ${ }^{2}$ (1) \\ ${ }^{1}$ Department of Surveying and Geoinformatics, Federal University of Technology, \\ Minna, Nigeria \\ ${ }^{2}$ Department of Surveying and Geoinformatics, Enugu state University of Technology, \\ Nssuka, Nigeria
}

\begin{abstract}
The need for dense and accurate gravity data cannot be overemphasised in the development of a precise gravimetric geoid model. Unfortunately, the field observations required are costly, and labour-intensive hence the need to ascertain via numerical simulations the appropriate field specifications before embarking on them. This paper presents an experimental study on the gravimetric data specifications (spatial resolution and data accuracy) required for achieving decimetre-level accuracy geoid using the conventional Stokes' Remove Compute Restore (RCR) method in Nigeria. A two-step solution approach was used in this study. The steps were determination of the (i) effect of data spacing by a comparative assessment of computation results obtained by using gravity data at four user determined intervals and (ii) effect of observation accuracy by numerical simulation using error propagation analysis. The data intervals $\left(3^{\prime} \times 3^{\prime}, 5^{\prime} \times 5^{\prime}, 10^{\prime} \times 10^{\prime}\right.$ and $20^{\prime} \times 20^{\prime}$ ) were selected from a combination of 1815 terrestrial FA anomaly points merged with EGM2008 derived FA anomaly covering the study area. Also, observational errors investigated were $0 \mathrm{mGal}, 0.1 \mathrm{mGal}, 0.5 \mathrm{mGal}, 1 \mathrm{mGal}$ and $5 \mathrm{mGal}$. The study was conducted in Nigeria having a total land area of approximately $923,768 \mathrm{~km}^{2}$. The study established that gravimetric geoid accuracy improves substantially as the spatial resolution and accuracy of the gravity data improves. Also, the study identified that data spacing contributes more to the overall geoid error than data accuracy. In addition, the study observed that hilly regions should have denser data spacing than plain areas. Within the test region, a data spacing of $3^{\prime} \times 3^{\prime}$ with gravity observational errors $5 \mathrm{mGal}$ was found to produce an acceptable gravimetric geoid. The produced gravimetric geoid had a pre-fit Root Mean Square Error (RMSE) of $15.6 \mathrm{~cm}$ when compared with GNSS-Levelling data at 27 stations located evenly across the study area. This large value obtained as the pre-fit RMSE can be attributed to the parametric inconsistencies in the Nigerian height system.
\end{abstract}

Key words: variance-covariance, Jacobian matrix, error propagation, geoid, height systems

\footnotetext{
${ }^{*}$ corresponding author: e-mail: joseph.odumosu@futminna.edu.ng, tel: +234 8065916462
} 


\section{Introduction}

The theory and study of geoid modelling is a long-term problem in geodesy with many methods and techniques resulting from the different research attempts. Among the several methods of geoid computation, the gravimetric method is, theoretically, the most preferred method since the geoid is actually an equi-potential surface of the Earth's gravity field (Ojinnaka, 2007; Sansò and Sideris, 2013).

Since the Stokes method of geoid modelling evolved in 1849, several modifications have been adopted for the implementation of gravimetric geoid model in order to improve the accuracy of the computed geoid. Some of these modifications include the Helmert's RCR technique which was modified after the conventional Stokes RCR method, Stokes-Helmert's method, the KTH Least squares modification of Stokes method (LSMC) with additive correction (AC) (Nsombo, 1996; Sjöberg and Featherstone, 2004) and the fast Fourier transform (FFT) approach (Akib and Aziz, 1996; AbdElmotaal, 2011). Notwithstanding the computational modification adopted, earlier studies have revealed that the overall geoid accuracy depends on the availability of a dense network of gravity data (Jekeli, 2012). Studies on seven national geoid models as presented in Table 1, confirm that the accuracy of the developed gravimetric geoid model depends largely on the amount of the gravity data used.

Aside from the data spacing, another important parameter in gravimetric geoid modelling is the accuracy of the gravity data. The effects of these two parameters (gravity data spacing and quality) on the overall geoid accuracy have been studied by some earlier researchers. Novák (2000) identified that a geoid accuracy of several centimetres could be achieved with $9 \mathrm{~km}$ data spacing (approx. $4.86^{\prime} \times 4.86^{\prime}$ ) if the data were error-free. Hong et al. (2009) studied the effects of gravity data quality and spacing on the accuracy of the computed geoid in the Helmert's RCR technique using simulated gravity data over South Korea. In the study, the geoid error was analysed and calculated by controlling the gravity data quality and spacing artificially. The results obtained were then compared with a reference geoid. The analysis performed show that geoid errors are mainly caused by the distribution of gravity data rather than by the noise in the data. He posited that gravity spacing smaller than $2 \mathrm{~km}$ is required to achieve a 5 -cm level of geoid accuracy. 
Table 1. Data spacing used for some regional geoid models (Odumosu, 2019).

\begin{tabular}{|c|c|c|c|c|c|c|c|}
\hline $\mathrm{S} / \mathrm{N}$ & Continent & Country & $\begin{array}{l}\text { Adopted } \\
\text { geoid }\end{array}$ & $\begin{array}{l}\text { No. of grav. } \\
\text { data points }\end{array}$ & $\begin{array}{l}\text { Approx. } \\
\text { data } \\
\text { spacing }\end{array}$ & $\begin{array}{l}\text { Accuracy } \\
\text { of geoid }\end{array}$ & Source \\
\hline 1 & $\begin{array}{l}\text { Africa } \\
\text { (East) }\end{array}$ & Tanzania & TZG08 & $\begin{array}{l}\mathrm{TD}=39,677 \\
\mathrm{MD}=57,722\end{array}$ & $\begin{array}{l}1 \text { point/ } \\
9.73 \mathrm{~km}^{2}\end{array}$ & $\begin{array}{l}\text { RMSE } \\
=27 \mathrm{~cm}\end{array}$ & $\begin{array}{l}\text { Ulotu } \\
\text { (2009) }\end{array}$ \\
\hline 2 & $\begin{array}{l}\text { Africa } \\
\text { (West) }\end{array}$ & Ghana & $\begin{array}{l}\text { Ghanan- } \\
\text { ian geoid }\end{array}$ & $\mathrm{TD}=10,081$ & $\begin{array}{l}1 \text { point/ } \\
24 \mathrm{~km}^{2}\end{array}$ & $\begin{array}{l}\text { RMSE } \\
=49.7 \mathrm{~cm}\end{array}$ & $\begin{array}{l}\text { Klu } \\
\text { (2015) }\end{array}$ \\
\hline 3 & $\begin{array}{l}\text { Africa } \\
\text { (North) }\end{array}$ & Egypt & & $\begin{array}{l}\mathrm{TD}=13,566 \\
\mathrm{MD}=121,480\end{array}$ & $\begin{array}{l}1 \text { point/ } \\
55 \mathrm{~km}^{2}\end{array}$ & $\begin{array}{l}\text { mean } \\
\text { residual } \\
(\mathrm{FFT}) \\
=1.52 \mathrm{~m} \\
\text { mean } \\
\text { residual } \\
(\mathrm{RCR}) \\
=1.05 \mathrm{~m}\end{array}$ & $\begin{array}{l}\text { Abd- } \\
\text { Elmotaal } \\
\text { (2011) }\end{array}$ \\
\hline 4 & $\begin{array}{l}\text { Africa } \\
\text { (South) }\end{array}$ & $\begin{array}{l}\text { South } \\
\text { Africa }\end{array}$ & & Not specified & $\begin{array}{l}1 \text { point/ } \\
6 \mathrm{~km}^{2}\end{array}$ & $\begin{array}{l}\text { RMSE } \\
=22 \mathrm{~cm}\end{array}$ & $\begin{array}{l}\text { Chandler } \\
\text { and Merry } \\
\text { (2010) }\end{array}$ \\
\hline 5 & $\begin{array}{l}\text { United } \\
\text { States of } \\
\text { America }\end{array}$ & Canada & & $\begin{array}{l}2.1 \text { million } \\
\text { terrestrial } \\
\text { points }\end{array}$ & $\begin{array}{l}1 \text { point } / \\
0.86 \mathrm{~km}^{2}\end{array}$ & $\begin{array}{l}\text { RMSE } \\
=4-8 \mathrm{~cm}\end{array}$ & $\begin{array}{l}\text { Wang et } \\
\text { al. (2012) }\end{array}$ \\
\hline 6 & Asia & Japan & $\begin{array}{l}\text { Japan } \\
\text { geoid }\end{array}$ & $\begin{array}{l}\mathrm{TD}=290,025 \\
\mathrm{MD}=580,000\end{array}$ & $\begin{array}{l}1 \text { point/ } \\
6 \mathrm{~km}^{2}\end{array}$ & $\begin{array}{l}\text { RMSE } \\
=7.8 \mathrm{~cm}\end{array}$ & $\begin{array}{l}\text { Matsuo et } \\
\text { al. (2016) }\end{array}$ \\
\hline 7 & Australia & $\begin{array}{l}\text { New } \\
\text { Zealand }\end{array}$ & $\begin{array}{l}\text { NZ geoid } \\
2009\end{array}$ & $\begin{array}{l}\mathrm{TD}=40,737 \\
\mathrm{MD}=1,300,266\end{array}$ & $\begin{array}{l}1 \text { point/ } \\
9.9 \mathrm{~km}^{2}\end{array}$ & $\begin{array}{l}\text { RMSE } \\
=58 \mathrm{~cm}\end{array}$ & $\begin{array}{l}\text { Amos } \\
\text { (2010) }\end{array}$ \\
\hline
\end{tabular}

$\mathrm{TD}=$ Terrestrial data

$\mathrm{MD}=$ Marine data

Huang et al. (2007) used variance component estimation (VCE) approach to estimate the geoid error in the Canadian gravimetric geoid. From the study, he identified total geoid error ranging from $1 \mathrm{~cm}$ to $32 \mathrm{~cm}$ across the Canadian land mass, when gravity data spacing of $2^{\prime} \times 2^{\prime}$ was used. Agren and Sjöberg (2012) investigated the gravity data requirement to compute the Swedish gravimetric geoid to an accuracy of $5 \mathrm{~mm}$ using the KTH LSMS with AC. The analysis was done by propagation of the errors in the terrestrial gravity observations and the EGM (Earth Gravitational Model) using variance-covariance model in the spectral domain and LSC (Least Squares Collocation). It was revealed that a minimum data spacing of $5 \mathrm{~km}$ without data gaps with a data noise between $0.1-0.5 \mathrm{mGal}$ is suitable to achieve $5 \mathrm{~mm}$ geoid accuracy using the KTH method. 
Farahani et al. (2017) assessed the surface gravity data requirements for a 5-mm quasi-geoid model considering the omission and commission errors. The study identified the relationship between omission error and data resolution as well as commission error and data accuracy. It was concluded that $3.5 \mathrm{~km}$ data spacing with an accuracy of $1.5 \mathrm{mGal}$ is needed to achieve a $5 \mathrm{~mm}$ quasi-geoid model over the Netherlands. Foroughi et al. (2019) tested the possibility of achieving sub-centimetre accuracy in gravimetric geoid computation using the Stokes-Helmert's by spherical approximations of the UNB (University of New Brunswick) approach. As a means of testing the accuracy of the proposed method, the uncertainties in the computed geoid were computed with respect to uncertainties in the downward continuation vis-à-vis the near zone (NZ) contribution, far zone (FZ) contribution, reference spheroid and transformation of the co-geoid back to the real space. The study discovered that maximum uncertainty was obtained from the downward continuation process with a value of $6 \mathrm{~cm}$ while the uncertainty of the topographic density was next being $5.6 \mathrm{~cm}$. Overall, a mean shift of $13.3 \mathrm{~cm}$ was obtained when the computed geoid was compared with GNSS/Levelling geoid at 75 control points regularly spaced around the study area.

Oršulić et al. (2019) affirmed that sub-centimetre accuracy geoid could be achieved not only by refinement in computational method but also by increasing the density (spacing) of the gravity data. The work utilized simulated data to demonstrate that improved RMSE (Root Mean Square Error) could be obtained in geoid modelling irrespective of the computational technique with increment in gravity data spacing. Also, Goli et al. (2019) investigated the effects of noise, spatial distribution and interpolation of ground gravity data on uncertainties of estimated geoid heights using the Stokes-Helmert approach. The study identified that randomly distributed (scattered) gravity points could not yield a 1-cm geoid if the average angular distance between scattered gravity points is larger than $1^{\prime}$. The study concluded that data noise of $\leq 1 \mathrm{mGal}$ is the most appropriate if a $1-\mathrm{cm}$ geoid is required.

The previous studies have examined the data requirements for accurate geoid modelling in different countries with emphasis on different geoid computation methods. This paper presents a similar study in Nigeria using the Stokes RCR technique with emphasis on achieving geoid accuracy $\leq 10 \mathrm{~cm}$. 
This is achieved by determining the effects of gravity data spacing and accuracy in gravimetric geoid computation across the study area.

\section{Error Propagation in gravimetric geoid computation}

Recall the conventional Stokes function as given in Hofmann-Wellenhof and Moritz (2005, p. 104) in Eq. (1a):

$N_{(\varphi, \lambda)}=\frac{R}{4 \pi \gamma} \iint S(\psi) \cdot \Delta g_{\left(\varphi^{\prime}, \lambda^{\prime}\right)} \mathrm{d} \sigma^{\prime}$,

where:

$$
\begin{aligned}
S(\psi)= & \left\{\operatorname{cosec}\left(\frac{\psi}{2}\right)-6 \sin \left(\frac{\psi}{2}\right)+1-5 \cos \psi-\right. \\
& \left.-3 \cos \psi \ln \left[\sin \left(\frac{\psi}{2}\right)+\sin ^{2}\left(\frac{\psi}{2}\right)\right]\right\},
\end{aligned}
$$

$\cos \psi=\sin \varphi \sin \varphi^{\prime}+\cos \varphi \cos \varphi^{\prime} \cos \left(\lambda^{\prime}-\lambda\right)$,

$\psi=\cos ^{-1}\left[\sin \varphi \sin \varphi^{\prime}+\cos \varphi \cos \varphi^{\prime} \cos \left(\lambda^{\prime}-\lambda\right)\right], \quad$ inverse cosine formula

$\varphi=$ latitude of computation point,

$\varphi^{\prime}=$ latitude of dummy point,

$\lambda=$ longitude of computation point,

$\lambda^{\prime}=$ longitude of dummy point,

$R=$ mean radius of the Earth.

Direct substitution of (1b) into (1a) yields Eq. (1d):

$$
\begin{aligned}
N_{(\varphi, \lambda)}=\frac{R \cdot \Delta g_{(\varphi, \lambda)}}{4 \pi \gamma} & \int_{\varphi}^{\varphi^{\prime}} \int_{\lambda}^{\lambda^{\prime}}\left\{\operatorname{cosec}\left(\frac{\psi}{2}\right)-6 \sin \left(\frac{\psi}{2}\right)+1-5 \cos \psi-\right. \\
& \left.-3 \cos \psi \ln \left[\sin \left(\frac{\psi}{2}\right)+\sin ^{2}\left(\frac{\psi}{2}\right)\right]\right\} \cos \varphi \mathrm{d} \lambda^{\prime} \mathrm{d} \varphi^{\prime} .
\end{aligned}
$$

In order to propagate for the error in the gravimetric geoid computation based on the quality of the gravity anomalies, Eq. (1d) could be re-written as Eq. (2), such that, Eq. (3) is the partial derivatives of the computed geoid with respect to the accuracy of the gravity anomaly: 


$$
\begin{aligned}
& N_{(\varphi, \lambda)}=\frac{R \cdot \Delta g_{(\varphi, \lambda)}}{4 \pi \gamma} \|\left\{\operatorname{cosec}\left(\frac{\psi}{2}\right)-6 \sin \left(\frac{\psi}{2}\right)+1-5 \cos \psi-\right. \\
& \left.-3 \cos \psi \ln \left[\sin \left(\frac{\psi}{2}\right)+\sin ^{2}\left(\frac{\psi}{2}\right)\right]\right\}\left.\left.\right|_{\varphi} ^{\varphi^{\prime}}\right|_{\lambda} ^{\lambda^{\prime}} \\
& \frac{\delta N}{\delta \Delta g_{(\varphi, \lambda)}}=\frac{R}{4 \pi \gamma}\left\{\operatorname{cosec}\left(\frac{\psi}{2}\right)-6 \sin \left(\frac{\psi}{2}\right)+1-5 \cos \psi-\right. \\
& \left.-3 \cos \psi \ln \left[\sin \left(\frac{\psi}{2}\right)+\sin ^{2}\left(\frac{\psi}{2}\right)\right]\right\} \text {. }
\end{aligned}
$$

By the Law of propagation of errors, the covariance matrix of adjusted parameters is as given in Eq. (4):

$\sum_{z z}=A \sigma_{0}^{2} A^{T}$

where:

$A=$ the Jacobian matrix of partials with respect to the gravity anomaly Eq. (3)),

$\sum_{z z}=$ co-variance matrix

$\sigma_{0}^{2}=$ variance of observations.

Eq. (3) shows the contribution of the gravity data quality to the computed geoid if there is no noise in the observed gravity data. However, if the gravity data is not errorless as often is the case, the observational noise is included in the computation of the co-variance matrix by the inclusion of variance of observations into Eq. (4). Therefore, the standard deviation of the computed gravimetric geoid is as shown in Eq. (5):

$\sigma_{N}=\sqrt{\left(\frac{\delta N}{\delta \Delta g} \cdot \sigma_{\Delta g}\right)^{2}}$,

$\sigma_{N}=$ standard deviation of gravimetric geoid,

$\sigma_{\Delta g}=$ standard error of the observed gravity data.

Eq. (5) is used to propagate for the effects of gravity data noise on computed gravimetric geoid by propagating for errors in the resulting gravimetric geoid at various levels of observational accuracy of the given data $\left(\sigma_{\Delta g}\right)$. 


\section{Study area}

This study was conducted using Nigeria as the test region. Nigeria has an approximate area of $923,768 \mathrm{~km}^{2}$ and a perimeter of about $4,000 \mathrm{~km}$. The longest east-west line measures about 1,200 km (from Kebbi state to Bornu state) and the longest north-southern stretch is about $1150 \mathrm{~km}$ (from Akwa Ibom state to Bornu state). The longest diagonal line stretches from Lagos State to Bornu State with a linear distance of about 1,400 km. Given the vast spatial extent, Nigeria is a highly undulating country that is composed both of planes, low-lands, deltas, plateaus and hills as shown in the digital terrain model of the country (Fig. 1). The highest trigonometric station in the country (N10) is located in Jos plateau with an orthometric height of $1396.075 \mathrm{~m}$ above MSL. An administrative map of the study area is shown in Fig. 2.

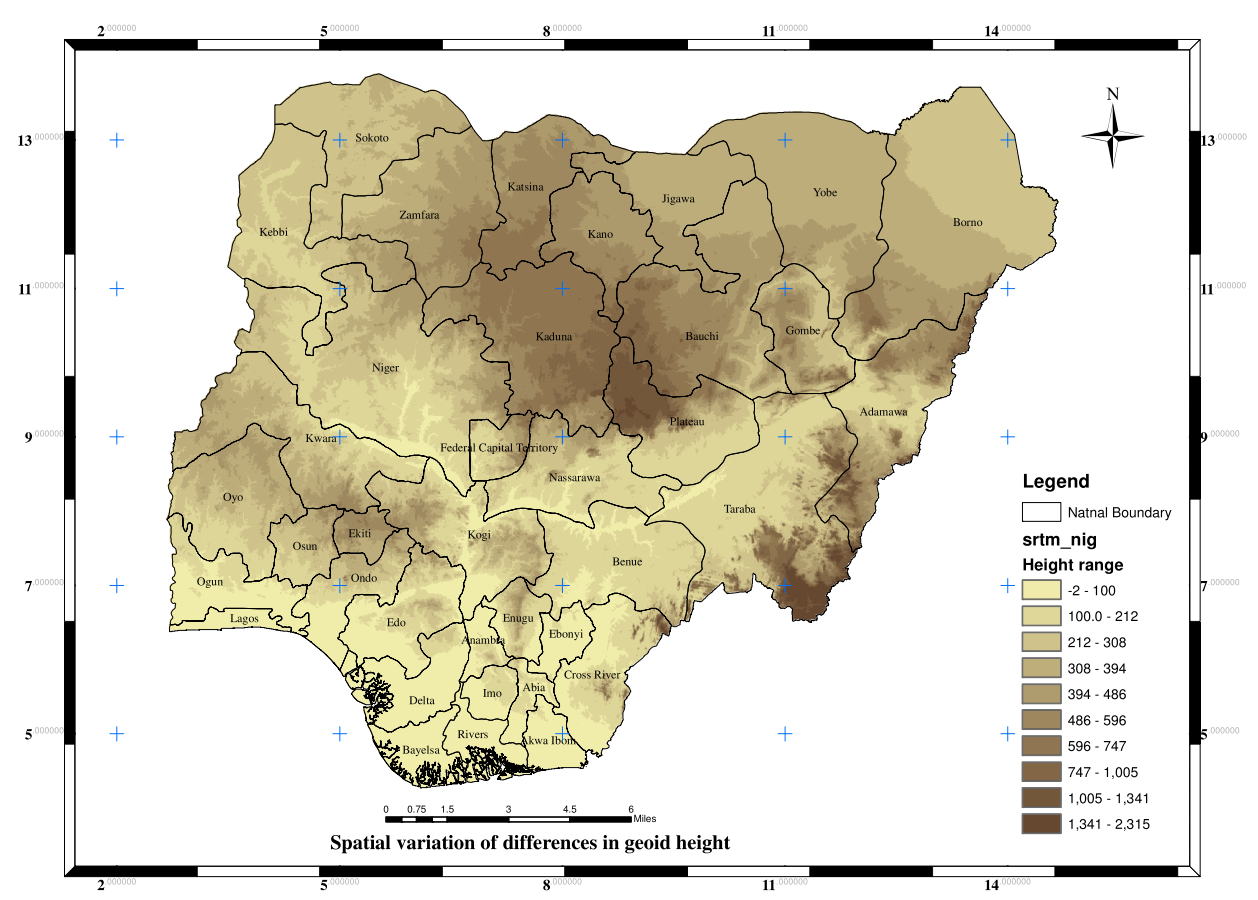

Fig. 1. Digital Elevation Model illustrating topography of the study area. 


\section{Materials}

The gravity data used for this study were obtained by merging 1815 Free Air (FA) anomaly gravity data points randomly distributed across the study area with EGM2008-derived FA anomaly. In order to ensure consistency between both datasets, corrections for omission error, commission error and atmospheric effects as recommended in earlier literature (Yahaya and $A z$ zab, 2019; Bomfim et al., 2013; Ellmann et al., 2009) were applied to the EGM2008 FA anomalies before merging them with the 1815 nation-wide adjusted gravity stations. The $1815 \mathrm{FA}$ anomaly points comprise of 62 points of the National Gravity Standardization Network (NGSN), 3 International Gravity Standardization Network (IGSN) stations (Osazuwa, 1995) and 1750 stations observed by multiple gravity missions across the country but had been uniformly adjusted by ordinary least squares (Odumosu, 2019).

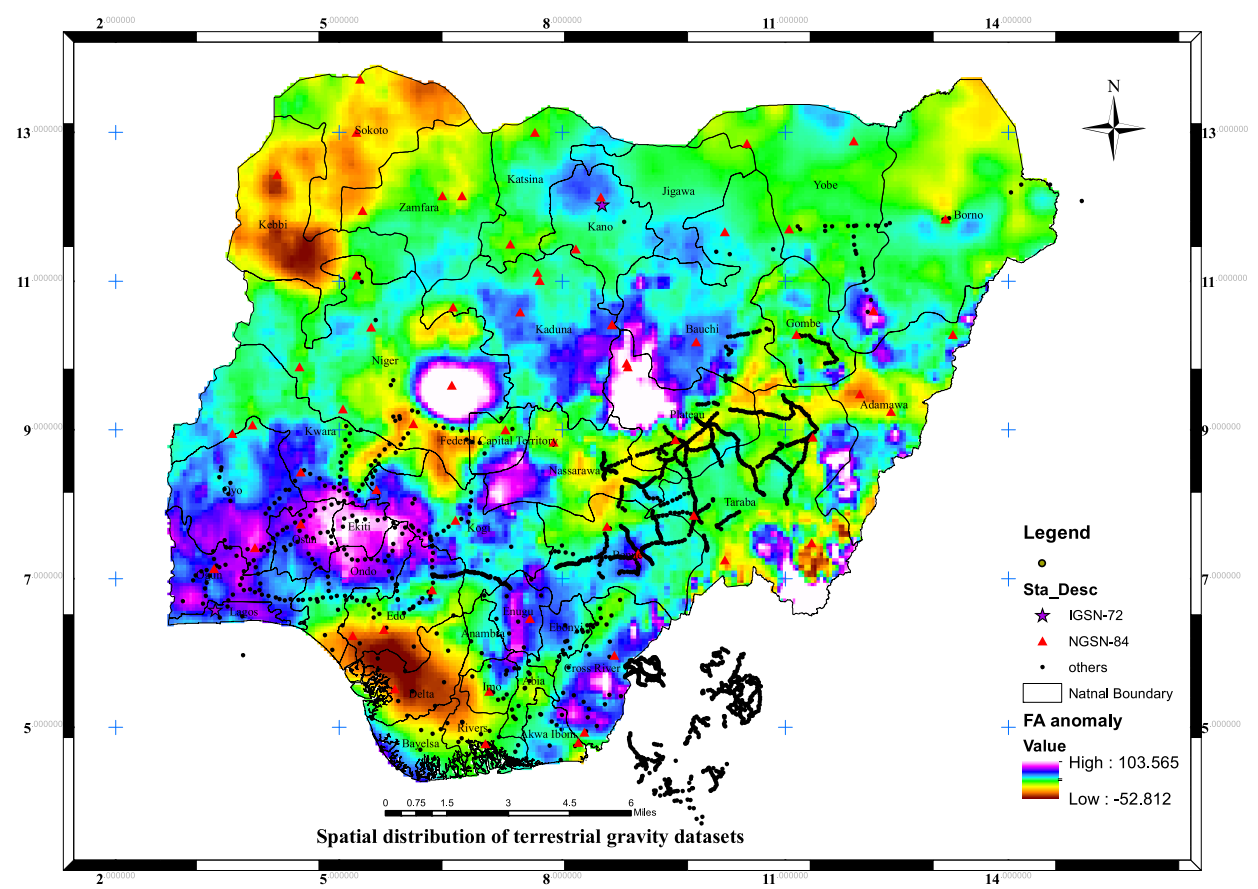

Fig. 2. Administrative map of Nigeria (study area) showing the spatial distribution of terrestrial gravity stations and merged FA anomaly variation. 
Table 2. Comparison of predicted gravity data at specified data interval with terrestrial data.

\begin{tabular}{|c|c|c|c|c|c|c|}
\hline \multirow[b]{2}{*}{$\mathrm{S} / \mathrm{N}$} & \multirow{2}{*}{$\begin{array}{c}\text { Data interval } \\
{[\text { minutes }]}\end{array}$} & \multirow{2}{*}{$\begin{array}{l}\text { No. of predicted } \\
\text { gravity points }\end{array}$} & \multirow{2}{*}{$\begin{array}{c}\text { Max } \\
{[\mathrm{mGal}]}\end{array}$} & \multirow{2}{*}{$\begin{array}{c}\text { Min } \\
{[\mathrm{mGal}]}\end{array}$} & \multicolumn{2}{|c|}{ Terrestrial data } \\
\hline & & & & & $\begin{array}{c}\text { Max } \\
{[\mathrm{mGal}]}\end{array}$ & $\begin{array}{c}\text { Min } \\
{[\mathrm{mGal}]}\end{array}$ \\
\hline 1 & $3^{\prime} \times 3^{\prime}$ & 52426 & 146.83 & -98.06 & \multirow{4}{*}{157.26} & \multirow{4}{*}{-47.54} \\
\hline 2 & $5^{\prime} \times 5^{\prime}$ & 15568 & 142.04 & -98.53 & & \\
\hline 3 & $10^{\prime} \times 10^{\prime}$ & 4545 & 129.85 & -93.42 & & \\
\hline 4 & $20^{\prime} \times 20^{\prime}$ & 1230 & 110.93 & -86.10 & & \\
\hline
\end{tabular}

After merging the terrestrial and EGM2008-derived FA anomalies, least squares collocation was used to determine gravity anomaly values at stipulated data intervals. Four data intervals were used in this study. Based on the utilized intervals, gravity values were predicted as shown in Table 2 . Graphical description of the spatial pattern of the obtained FA anomaly after merging the datasets is shown in Fig. 2 with the 1815 gravity data superimposed on it.

\section{Methods}

This experimental study was conducted by using the steps presented in Fig. 3. The steps were sequentially followed in order to limit computational errors in the determined geoid. The study methodology can generally be summarized as follows:

a) The effects of data spacing was determined by a comparative assessment of computation results obtained by using gravity data at four (4) user determined intervals while,

b) The effect of data noise was numerically simulated by error propagation analysis.

The data reduction was carried out using the complete Bouguer reduction method as presented in Eqs. (6)-(7). The complete Bouguer reduction was chosen because it produces smooth gravity anomalies that are easy and accurate to predict (Bajracharya, 2003):

$\Delta g_{F A}=g_{o b s}-\gamma-\delta g_{B}+T C$, 


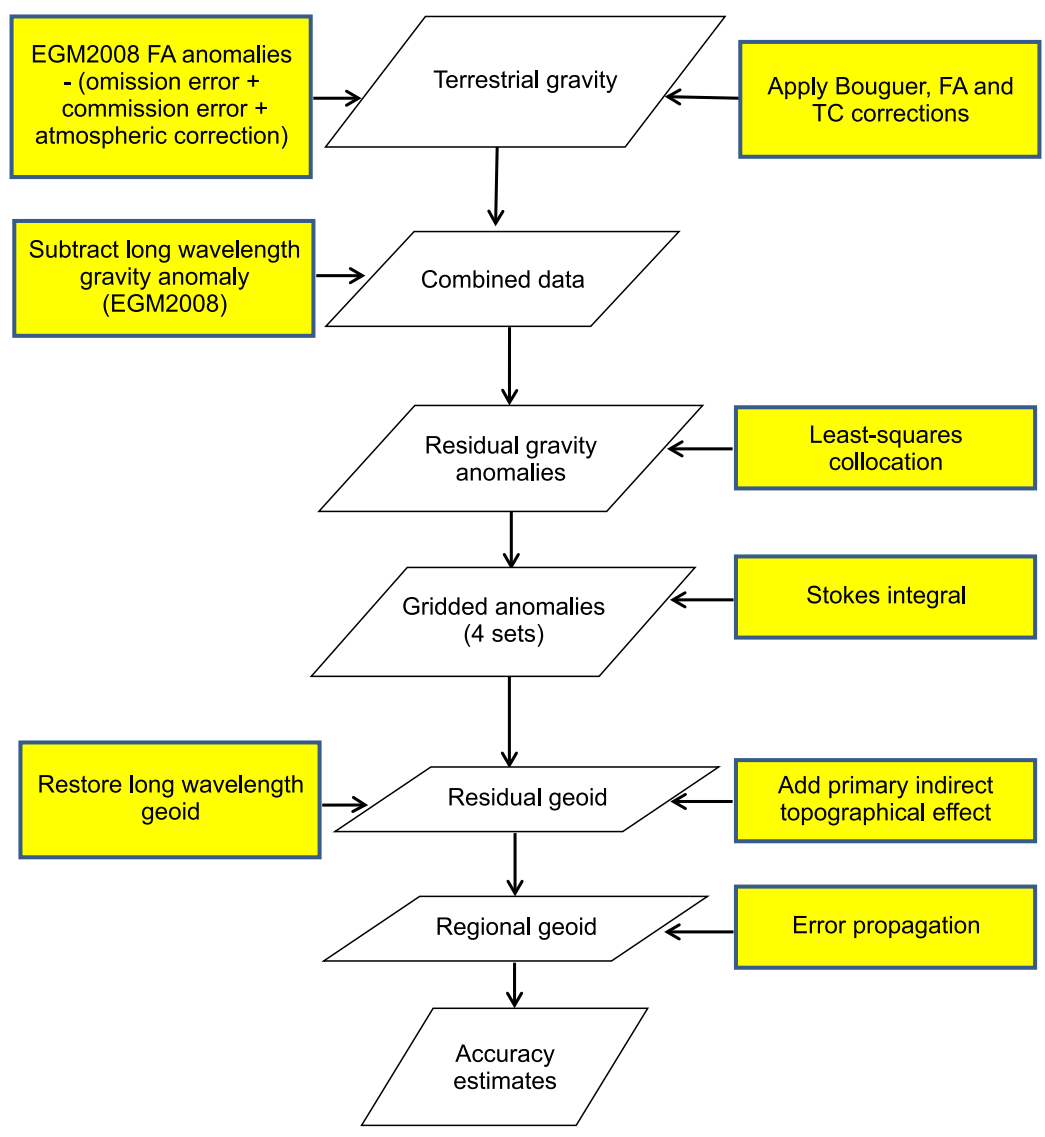

Fig. 3. Work flow diagram describing the RCR method as implemented in this study.

$\Delta g_{\text {res }}=\Delta g_{F A}-\Delta g_{G G M}$,

where:

$\Delta g_{\text {res }}=$ residual FA gravity anomaly,

$\Delta g_{\text {bouguer }}=$ free air anomaly,

$g_{\text {obs }}=$ observed gravity values,

$\gamma=$ normal gravity,

$\delta g_{B}=$ complete Bouguer reduction (free air correction + Bouguer correction),

$T C=$ terrain correction. 
In order to satisfy the theoretical assumption that all masses must be compressed beneath the geoid and given the high topographic undulation across the study area, a terrain correction $(T C)$ was applied to the complete Bouguer reduction. The Hammer chart method of a terrain correction was used with inner and outer zone distances of $1 \mathrm{~km}$ and $166 \mathrm{~km}$, respectively. This was done using the QCtool software with topographic data obtained from a 1 arc seconds SRTM - DTM of the study area.

As a result of the very sparse gravity data, the data voids were filled using EGM2008-derived FA anomalies. In order to ensure consistency between the EGM2008 anomalies and the terrestrial anomalies, corrections for omission error, commission error and atmospheric effects were applied to the EGM data before merging them, Although other data merging methods such as the padding and spectral method exist, this data merger procedure is preferred based on recommendations from some earlier literature (Yahaya and Azzab, 2019; Elmann et al., 2009).

The long wavelength contribution on the gravity anomaly was then removed from the merged gravity anomaly. The long wavelength contributions were computed by evaluating Eq. (10) using the EGM96 (Earth's Gravity Model of 1996) parameters. The choice of EGM96 model was based on preliminary comparative analysis of the suitability of EGM96 and EGM2008 over Nigeria (Odumosu, 2019):

$$
\begin{aligned}
\Delta g_{G G M}=\frac{G M}{R^{2}} \sum_{n=1}^{m}\left(\frac{a}{R}\right)^{2}(n-1) \times \\
\quad \times \sum_{m=0}^{n}\left[C_{n m} \cos (m \lambda)+S_{n m} \sin (m \lambda)\right] P_{n m}(\cos (\theta)),
\end{aligned}
$$

$\Delta g_{G G M}=$ long wavelength portion of the gravity anomaly, $G M=$ gravity-mass constant of Earth gravity model (EGM96) 1996, $a=$ equatorial scale factor of EGM96,

$n=$ degree of harmonic expansion,

$m=$ order of harmonic expansion of EGM96,

$\lambda=$ longitude of computation station,

$R=$ mean radius of the Earth,

$P_{n m}=$ fully-normalized Legendre function,

$C_{n m}, S_{n m}=$ fully-normalised coefficients of EGM96 to degree and order 360 . 
The least squares collocation (LSC) approach was used for residual anomaly prediction across the study area at the required interval. Given the predicted gravity values at desired intervals as shown in Table 2, residual geoid was repetitively computed using Eq. (1d). After computing the residual geoid, the indirect effect of topography on the geoid is computed as well as the long wavelength effects of the geoid using Eqs. (9) and (10), respectively. These are then restored to the residual geoid to give the final geoid as mathematically expressed in Eq. (11):

$N_{\text {ind }}(P)=\frac{-\pi G \rho H_{P}^{2}}{\gamma}-\frac{G \rho R^{2}}{6 \gamma} \int_{\sigma} \frac{H^{3}-H_{P}^{3}}{l^{3}} \mathrm{~d} \sigma$,

where:

$N_{\text {ind }}=$ primary indirect topographic effect,

$G=$ gravitational constant,

$\rho=$ topographic density,

$H_{P}^{2}=$ orthometric height at station $P$.

$R=$ radius of the Earth,

$\mathrm{d} \sigma=$ element of volume,

$l=$ distance between point on the Earth surface and the geoid,

$\gamma=$ normal gravity.

$$
\begin{aligned}
N_{G G M}=\frac{G M}{r \gamma} \sum_{n=2}^{m}\left(\frac{a}{r}\right)^{n} \times \\
\quad \times \sum_{m=0}^{n}\left[\bar{C}_{n m} \cos (m \lambda)+\bar{S}_{n m} \sin (m \lambda)\right] P_{n m}(\cos (\theta)),
\end{aligned}
$$

where:

$N_{G G M}=$ long wavelength contributions to the geoid,

$N=N_{\text {res }}+N_{\text {ind }}+N_{N G G}$.

In order to determine the effect of gravity data quality on the computed geoid, error propagation analysis was performed using Eq. (5).

\section{Results and discussion}

Results obtained in this study were used to infer the effects of gravity data spacing/interval and accuracy on gravimetric geoid computation using the 
Stokes' RCR method.

\subsection{Effect of data spacing on gravimetric geoid computation}

Fig. 4 shows the gravimetric geoid model of the study area computed with gravity data at $3^{\prime}$ by $3^{\prime}, 5^{\prime}$ by $5^{\prime}, 10^{\prime}$ by $10^{\prime}$ and $20^{\prime}$ by $20^{\prime}$ data interval. Although, similar pattern is observed in the spatial characteristics of the computed geoid at all the specified data intervals as seen in Fig. 4; significant amount of details are lost with a decrease in spatial resolution of the gravity data used for the geoid computation. In all cases, the largest geoid values are noticed around the South western to the North central regions of the country while the lowest values occur near the extreme Northern region. The similarity in the trend suggests that irrespective of the data spacing,

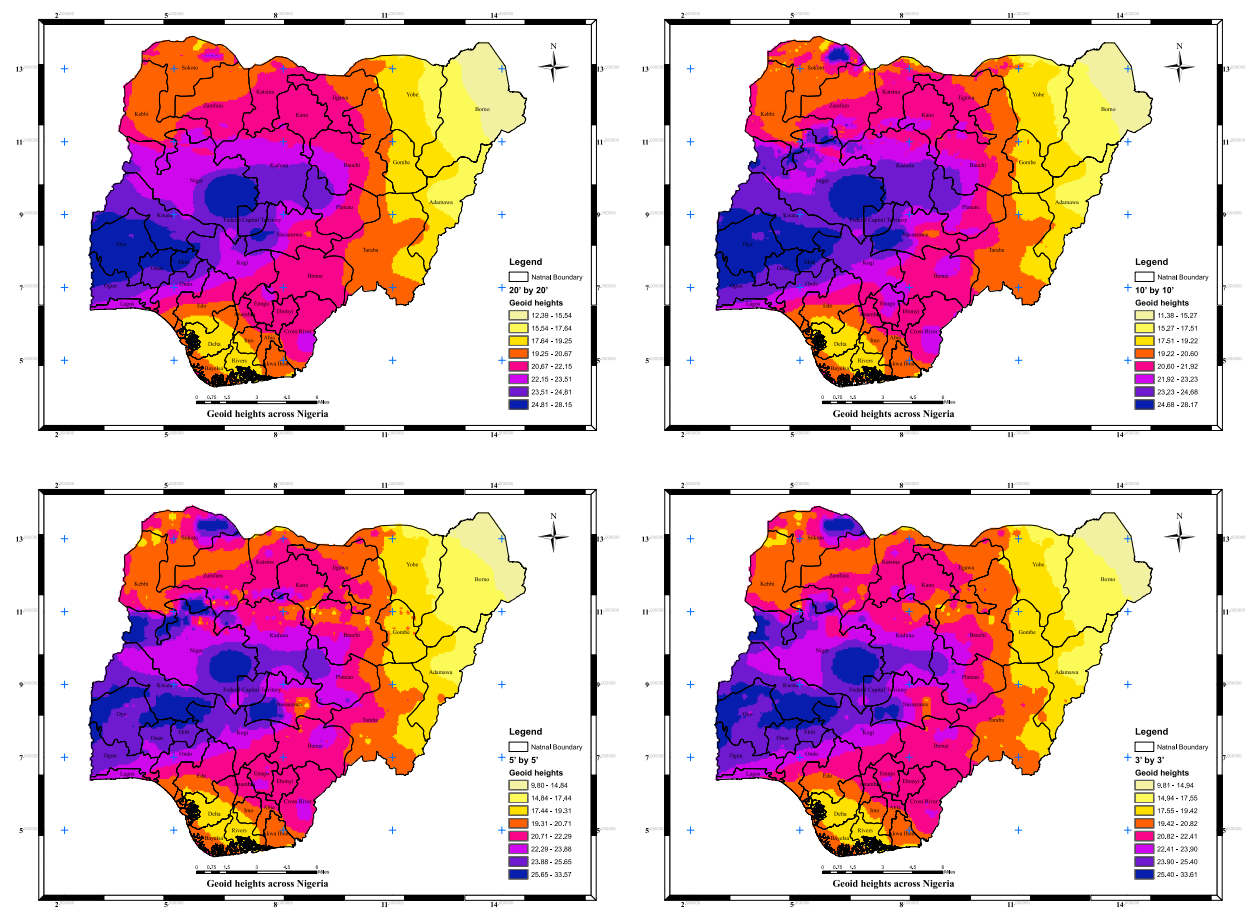

Fig. 4. Geoid heights across Nigeria at (upper left) $20^{\prime} \times 20^{\prime}$, (upper right) $10^{\prime} \times 10^{\prime}$, (lower left) $5^{\prime} \times 5^{\prime}$ and (lower right) $3^{\prime} \times 3^{\prime}$ gravity data interval. 
approximate models of a regional geoid could be obtained especially for applications that do not require high geoid accuracies (Bruton, 2000).

Fig. 5 presents a graphical assessment of the difference between the four models which may not be obvious by visual examination. Since the $3^{\prime}$ by $3^{\prime}$ data spacing is the finest data grid available, the result obtained from it is taken as the reference geoid from which the other models were subtracted. This was achieved by converting the computed geoid values into raster maps as shown in Fig. 4 using the Quantum GIS software. Thereafter, the raster calculator was used to perform the spatial algebraic operation as seen in Fig. 5 .

Assessment of the spatial pattern of the differences in the geoid height as shown in Fig. 5 indicates that the differences are randomly distributed. Further to this, comparison of these differences with the topography of the
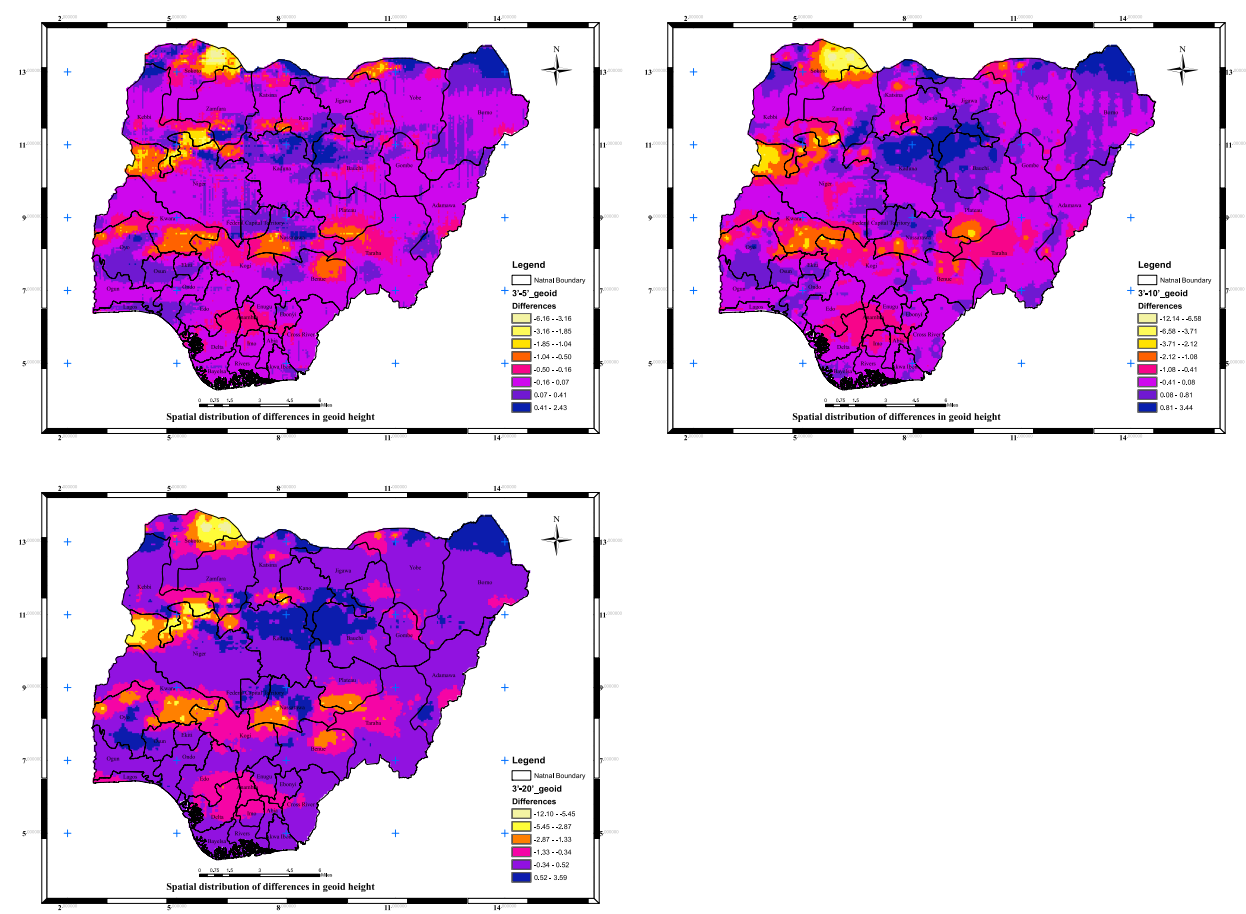

Fig. 5. Geoidal differences between model obtained from $3^{\prime} \times 3^{\prime}$ data interval and (upper left) $5^{\prime} \times 5^{\prime}$, (upper right) $10^{\prime} \times 10^{\prime}$ and (lower left) $20^{\prime} \times 20^{\prime}$ gravity data interval. 
study area (Fig. 1) shows that the large differences are seen in mountainous regions as the spatial interval increases from $5^{\prime} \times 5^{\prime}$ to $20^{\prime} \times 20^{\prime}$. This result conforms to the findings of Oršulić et al. (2019), which recommends denser grids in high elevation areas.

Similarly, it is observed that the range of differences increases as the data interval used in computation increases from $5^{\prime} \times 5^{\prime}$ to $20^{\prime} \times 20^{\prime}$. The pie charts shown in Fig. 6 indicate that as the spatial resolution of gravity data get poorer, the error in geoid height obtained increases. This is further ascertained by comparing the computed geoid models with GNSS-Levelling data at 27 stations across Nigeria (Fig. 7). The RMSE obtained by comparing gravimetric results at the various intervals with GNSS-Levelling data indicate that geoid accuracy decreases as data resolution reduces (Table 3). This is inferred as the RMSE increases from $15.6 \mathrm{~cm}$ when gravity data
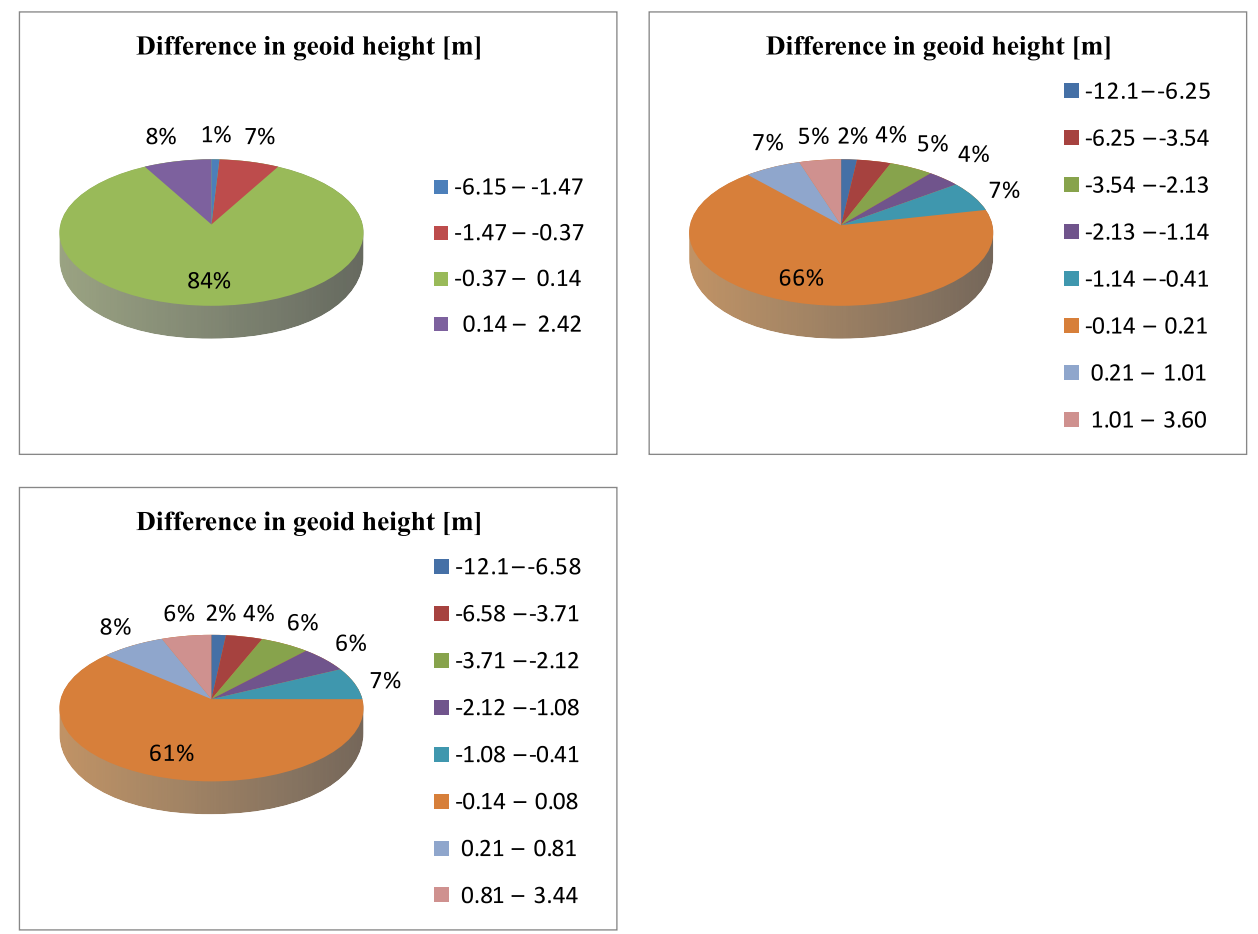

Fig. 6. Range and spread of differences in geoid height computed from data at $3^{\prime} \times 3^{\prime}$ and (upper left) $5^{\prime} \times 5^{\prime}$, (upper right) $10^{\prime} \times 10^{\prime}$, (lower left) $20^{\prime} \times 20^{\prime}$ interval. 


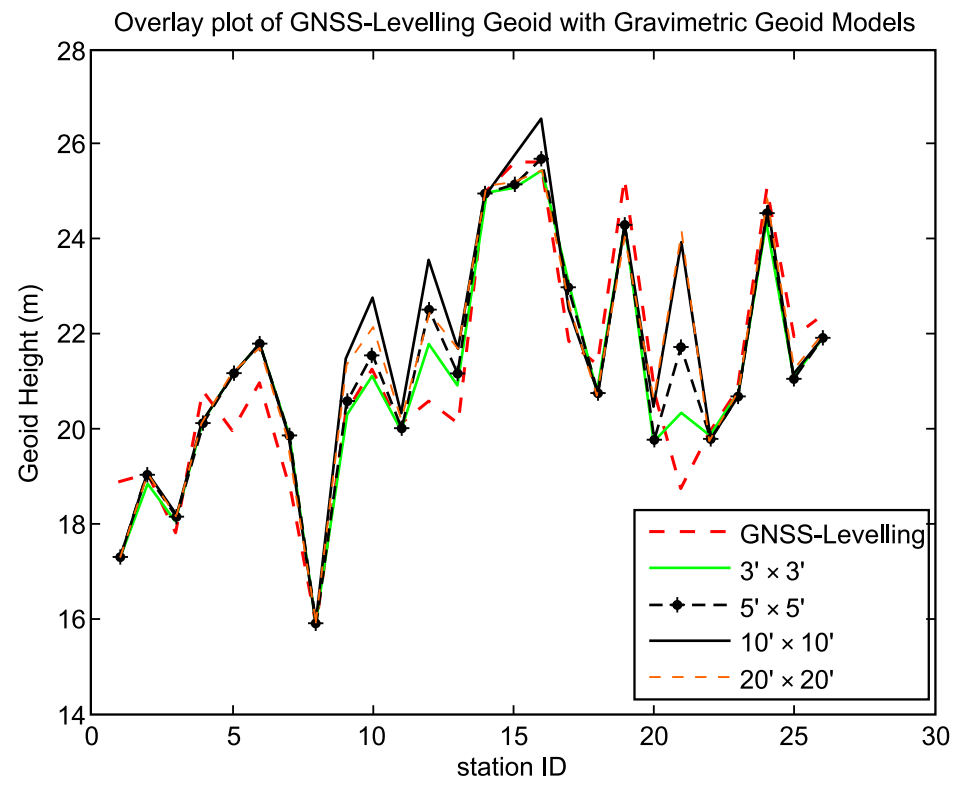

Fig. 7. Overlay plot of GNSS-Levelling values and gravimetric geoid values at GNSSLevelling stations.

Table 3. Statistics of pre-fit difference between gravimetric geoid and GNSS/Levelling geoid.

\begin{tabular}{|c|c|r|r|r|r|}
\hline & Statistics & $3^{\prime} \times \mathbf{3}^{\prime}$ & $5^{\prime} \times 5^{\prime}$ & $10^{\prime} \times 10^{\prime}$ & $20^{\prime} \times 20^{\prime}$ \\
\hline \multirow{4}{*}{ Check of gravimetric geoid at } & Max diff & 1.684 & 1.614 & 1.630 & 1.644 \\
\cline { 2 - 6 } 27 GNSS/Leveling stations [m] & Min diff & -1.598 & -2.994 & -5.555 & -5.223 \\
\cline { 2 - 6 } & Std dev & 0.797 & 0.981 & 1.316 & 1.356 \\
\cline { 2 - 6 } & RMSE & 0.156 & 0.194 & 0.267 & 0.281 \\
\hline
\end{tabular}

with $3^{\prime} \times 3^{\prime}$ grid interval is used to $28.1 \mathrm{~cm}$ when data with $20^{\prime} \times 20^{\prime}$ interval is used for the computation. This result also conforms to earlier studies which infer that the accuracy of geoid models increases as data spacing/interval becomes denser and regular (Goli et al., 2019; Hong et al., 2009).

Furthermore, the pie charts show that as the data spacing increases, large error-range would be observed at more locations within the study area. This is why while $84 \%$ of the study area had differences between -37 to $14 \mathrm{~cm}$ when the $5^{\prime} \times 5^{\prime}$ interval is used, $66 \%$ of the study area had differences of similar range $(-14$ to $21 \mathrm{~cm})$ when the $10^{\prime} \times 10^{\prime}$ interval was used. 


\subsection{Effect of data quality on gravimetric geoid computation}

The results presented in section 6.1 are based on the assumption that there are no errors in the gravity data used for the gravimetric geoid computation. However, since it is practically impossible to achieve an errorless gravity observation, the effects of the gravimetric data quality on the computed geoid is herein investigated. This is done by using the theory of random error propagation to numerically simulate the effects of data noise on the accuracy of the computed geoid. At each data interval, error propagation analysis was done based on assumptions that the gravity data had the standard errors of $0.1 \mathrm{mGal}, 0.5 \mathrm{mGal}, 1 \mathrm{mGal}$ and $5 \mathrm{mGal}$. The results obtained (Tables 4a-d) indicate that the effect of data noise on computed geoid increases as data spacing also increases.

Table 4 a shows that data noise of $\pm 0.1 \mathrm{mGal}$ contributes less than $0.1 \mathrm{~cm}$ error in gravimetric geoid irrespective of the data spacing. Similarly, Table $4 \mathrm{~b}$ shows that the maximum error contribution from data noise of $0.5 \mathrm{mGal}$ is $\pm 0.7 \mathrm{~cm}, \pm 1.5 \mathrm{~cm}, \pm 2.3 \mathrm{~cm}$ and $\pm 2.3 \mathrm{~cm}$ at $3^{\prime}, 5^{\prime}, 10^{\prime}$ and $20^{\prime}$ data spacing, respectively. It also tells that the minimum error contribution from data noise would range from $\pm 0.1 \mathrm{~mm}$ at $3^{\prime} \times 3^{\prime}$ data interval to $\pm 1 \mathrm{~mm}$ at $20^{\prime} \times 20^{\prime}$ data interval. On the average, the error contribution of $0.5 \mathrm{mGal}$ data noise range from $\pm 1 \mathrm{~mm}$ to $\pm 3 \mathrm{~cm}$. From Table $4 \mathrm{~d}$, it is seen that the maximum error obtainable in gravimetric geoid computation as a result of data noise of $5 \mathrm{mGal}$ are $72 \mathrm{~cm}, 1.59 \mathrm{~m}, 2.34 \mathrm{~m}$ and $2.34 \mathrm{~m}$ at $3^{\prime}, 5^{\prime}, 10^{\prime}$ and $20^{\prime}$ data spacing respectively within the study area.

Generally, the accuracy obtainable in the gravimetric geoid reduces as the data noise increases from $0.1 \mathrm{mGal}$ to $5 \mathrm{mGal}$. It should also be observed that the effect of data noise increases when data spacing is large. This trend of a decreasing accuracy in computed gravimetric geoid with decrease in observational accuracy and spatial resolution validates earlier studies that a dense gravity network is essential for an accurate gravimetric geoid modelling (Oršulić et al., 2019). Table 5 presents a summary of the average error contribution of data noise on computed gravimetric geoid based on the simulated observational accuracies at the investigated data intervals.

From the summary of the results of the error propagation analysis as presented in Table 5, data noise of $0.1-5 \mathrm{mGal}$ are permissible for decimetre-level $(\leq 10 \mathrm{~cm})$ accuracy in geoid modelling provided that the data spacing does not exceed $3^{\prime} \times 3^{\prime}$. However, with a spatial resolution of $5^{\prime} \times 5^{\prime}$, 
Table 4a. Statistics of geoid accuracy $\left(\sigma_{N}\right)$ assuming observational standard deviation is $0.1 \mathrm{mGal}$.

\begin{tabular}{|c|c|c|c|c|c|}
\hline $\begin{array}{c}\text { Simulation } \\
\text { assumptions }\end{array}$ & Statistics & $3^{\prime} \times 3^{\prime}$ & $5^{\prime} \times 5^{\prime}$ & $10^{\prime} \times 10^{\prime}$ & $20^{\prime} \times 20^{\prime}$ \\
\hline \multirow{2}{*}{$\begin{array}{c}\text { gravity obs accuracy } \\
=0.1 \text { mGal }\end{array}$} & $\min [\mathrm{m}]$ & 0.0001 & 0.0001 & 0.0001 & 0.0001 \\
\cline { 2 - 6 } & $\max [\mathrm{m}]$ & 0.0003 & 0.0006 & 0.0008 & 0.0009 \\
\cline { 2 - 6 } & average $[\mathrm{m}]$ & 0.0001 & 0.0001 & 0.0002 & 0.0002 \\
\hline
\end{tabular}

Table $4 \mathrm{~b}$. Statistics of geoid accuracy $\left(\sigma_{N}\right)$ assuming observational standard deviation is $0.5 \mathrm{mGal}$.

\begin{tabular}{|c|c|c|c|c|c|}
\hline $\begin{array}{c}\text { Simulation } \\
\text { assumptions }\end{array}$ & Statistics & $3^{\prime} \times 3^{\prime}$ & $5^{\prime} \times 5^{\prime}$ & $10^{\prime} \times 10^{\prime}$ & $20^{\prime} \times 20^{\prime}$ \\
\hline \multirow{2}{*}{$\begin{array}{c}\text { gravity obs accuracy } \\
=0.5 \text { mGal }\end{array}$} & $\min [\mathrm{m}]$ & 0.0001 & 0.0002 & 0.0004 & 0.0005 \\
\cline { 2 - 6 } & $\max [\mathrm{m}]$ & 0.0073 & 0.0158 & 0.0234 & 0.0234 \\
\cline { 2 - 6 } & average $[\mathrm{m}]$ & 0.0006 & 0.0017 & 0.0290 & 0.0300 \\
\hline
\end{tabular}

Table 4c. Statistics of geoid accuracy $\left(\sigma_{N}\right)$ assuming observational standard deviation is $1 \mathrm{mGal}$.

\begin{tabular}{|c|c|c|c|c|c|}
\hline $\begin{array}{c}\text { Simulation } \\
\text { assumptions }\end{array}$ & Statistics & $3^{\prime} \times 3^{\prime}$ & $5^{\prime} \times 5^{\prime}$ & $\mathbf{1 0}^{\prime} \times 10^{\prime}$ & $20^{\prime} \times 20^{\prime}$ \\
\hline \multirow{2}{*}{$\begin{array}{c}\text { gravity obs accuracy } \\
=1 \mathrm{mGal}\end{array}$} & $\min [\mathrm{m}]$ & 0.0003 & 0.0007 & 0.0017 & 0.0019 \\
\cline { 2 - 6 } & $\max [\mathrm{m}]$ & 0.0292 & 0.0634 & 0.0937 & 0.0937 \\
\cline { 2 - 6 } & average $[\mathrm{m}]$ & 0.0024 & 0.0067 & 0.0114 & 0.0119 \\
\hline
\end{tabular}

Table 4 d. Statistics of geoid accuracy $\left(\sigma_{N}\right)$ assuming observational standard deviation is 5 mGal.

\begin{tabular}{|c|c|c|c|c|c|}
\hline $\begin{array}{c}\text { Simulation } \\
\text { assumptions }\end{array}$ & Statistics & $3^{\prime} \times 3^{\prime}$ & $5^{\prime} \times 5^{\prime}$ & $1^{\prime} \times 10^{\prime}$ & $20^{\prime} \times 20^{\prime}$ \\
\hline \multirow{2}{*}{$\begin{array}{c}\text { gravity obs accuracy } \\
=5 \text { mGal }\end{array}$} & $\min [\mathrm{m}]$ & 0.0066 & 0.0177 & 0.0417 & 0.0469 \\
\cline { 2 - 6 } & $\max [\mathrm{m}]$ & 0.7289 & 1.5849 & 2.3420 & 2.3420 \\
\cline { 2 - 6 } & average $[\mathrm{m}]$ & 0.0604 & 0.1664 & 0.8520 & 0.9283 \\
\hline
\end{tabular}

the maximum allowable data noise is $1 \mathrm{mGal}$. In datasets with spatial interval that exceed $10^{\prime} \times 10^{\prime}$ observational accuracies not greater than $0.1 \mathrm{mGal}$ is required if decimetre-level accuracy gravimetric geoid is to be achieved. Furthermore, comparing the values in Table 5 to the error contributions obtained from data spacing (Fig. 6), we conclude that data spacing has 
Table 5. Average error contribution of different noise levels to computed gravimetric geoid at investigated data intervals.

\begin{tabular}{|c|c|c|c|c|}
\hline $\begin{array}{c}\text { Assumed accuracy of } \\
\text { gravity observations }\end{array}$ & $3^{\prime} \times 3^{\prime}$ & $5^{\prime} \times 5^{\prime}$ & $10^{\prime} \times 10^{\prime}$ & $20^{\prime} \times 20^{\prime}$ \\
\hline $0.1[\mathrm{mGal}]$ & 0.0001 & 0.0001 & 0.0002 & 0.0002 \\
\hline $0.5[\mathrm{mGal}]$ & 0.0006 & 0.0017 & 0.0290 & 0.0300 \\
\hline $1[\mathrm{mGal}]$ & 0.0024 & 0.0067 & 0.0114 & 0.0119 \\
\hline $5[\mathrm{mGal}]$ & 0.0604 & 0.1664 & 0.8520 & 0.9283 \\
\hline
\end{tabular}

greater effects on gravimetric geoid computation than data quality (Jekeli et al., 2009; Hong et al., 2009).

Consequently, upon the significant improvement in the accuracy of the computed gravimetric geoid with enhancement in spatial resolution and observational accuracy of the gravity data, it is suggested that $10 \mathrm{~cm}$ geoid could be achieved by the Stokes RCR method within the study area provided that the gravity data has a dense spatial resolution $\left(\leq 3^{\prime} \times 3^{\prime}\right)$ and observational noise of less than $5 \mathrm{mGal}$. Also, given the importance of topography to geoid modelling, it should be emphasized that these accuracy measures can only be guaranteed in areas with topographic range that do not exceed 1,396 $\mathrm{m}$ above MSL as found within the study area. Hence, in more hilly terrain, denser data spacing and better observational accuracy might be required for centimetre level accuracy with the Stokes RCR method.

\section{Conclusion}

The gravity data requirements for decimetre-level accuracy geoid have been evaluated in this study. This has been achieved by a combination of a comparative assessment of repetitive computation at user-specified resolutions and error propagation analysis. Obtained results confirm the reliability of the conventional Stokes RCR method to achieve decimetre-level accuracy geoid provided that the appropriate gravity data requirements are given. The study further affirms that a dense data grid is more crucial for an accurate geoid modelling rather than data observation accuracy i.e. the effect of the gravity data spatial resolution on the geoid accuracy is more important than the data noise. It was also identified that high elevation areas 
require denser data grids than low elevation areas. For the test region, a data spacing of $3^{\prime} \times 3^{\prime}$ with gravity observational errors $\leq 5 \mathrm{mGal}$ was found to produce an acceptable gravimetric geoid. The study also identified that the error contribution of data noise is lesser than that of the data spacing. Given the difficulty in achieving high accuracy in gravity data observation (especially on large expanse), this study recommends that a dense data interval of less than $3^{\prime} \times 3^{\prime}$ should be considered for field observations. This dense data grid would compensate for the observational errors incurred during the field observation as long as the errors are within $5 \mathrm{mGal}$. Therefore, it is recommended that if high observational accuracy cannot be guaranteed, then a denser data network would be required.

The produced geoid had a pre-fit RMSE of $15.6 \mathrm{~cm}$ when compared with GNSS-Levelling geoid at 27 GNSS-Levelling stations distributed well across the country. The pre-fit RMSE is considered acceptable due to some parametric distortions inherent in the Nigerian height system as discussed by Isioye et al. (2010) and Odumosu et al. (2018). Hence, achieving a prefit accuracy of $15.6 \mathrm{~cm}$ suggests that the developed gravimetric geoid is reliable.

\section{References}

Abd-Elmotaal H. A., 2011: FFT versus Least squares collocation techniques for gravimetric geoid determination in Egypt. J. Appl. Geophys., Egypt. Soc. Appl. Petrophys., 10, 1, 121-133.

Akib W. M., Aziz W. A., 1996: The Use of FFT Method in Geoid Modelling. Buletin Ukur, 7, 2, 119-131, ISSN 0128-4274, http://eprints.utm.my/id/eprint/4889/1/ TheUse.pdf.

Amos M. J., 2010: New Zealand vertical datum 2009. New Zealand Surveyor, 300, 5-16. Ågren J., Sjöberg L. E., 2012: Investigations of the requirements for a future $5 \mathrm{~mm}$ quasigeoid model over Sweden. Gravity, Geoid and Height Systems (GGHS) conference, Venice, Italy, organized by the IAG commission 2. $9^{\text {th }}-12^{\text {th }}$ October, 2012.

Bajracharya S., 2003: Terrain effects on geoid determination. MSc dissertation, Department of Geomatics Engineering, University of Calgary, doi : 10.11575/PRISM/15283.

Bomfim E. P, Braitenberg C., Molina E. C., 2013: Mutual evaluation of global gravity models (EGM2008 and GOCE) and terrestrial data in Amazon Basin, Brazil. Geophys. J. Int., 195, 2, 870-882, doi: 10.1093/gji/ggt283.

Bruton A. M., 2000: Improving the Accuracy and Resolution of SINS/DGPS Airborne Gravimetry. PhD Thesis, Department of Geomatics, University of Calgary, https: //www. ucalgary.ca/engo_webdocs/KPS/00.20145. AMBruton.pdf. 
Chandler G., Merry C., 2010: The South African Geoid 2010: SAGeoid10. Position IT, June, 2010, 29-33.

Ellmann A., Kaminskis J., Parselinas E., Jürgenson H., Oja T., 2009: Evaluation results of the Earth Gravitational Model EGm08 over the Baltic countries. Newton's Bulletin, 4, 110-121.

Farahani H. H., Klees R., Slobbe C., 2017: Data requirements for a 5-mm quasi-geoid in the Netherlands. Studia Geophys. et Geod., 61, 4, 675-702, doi: 10.1007/s11200016-0171-7.

Foroughi I., Vaníek P., Kingdon R. W., Goli M., Sheng M., Afrasteh Y., Novák P., Santos M. C., 2019: Sub-centimetre geoid. J. Geod., 93, 6, 849-868, doi: 10.1007/s00190 -018-1208-1.

Goli M., Foroughi I., Novák P., 2019: The effect of the noise, spatial distribution, and interpolation of ground gravity data on uncertainties of estimated geoidal heights. Studia Geophys. et Geod., 63, 1, 35-54, doi: 10.1007/s11200-018-1013-6.

Hofmann-Wellenhof B., Moritz H. 2005: Physical geodesy, 2nd edition. Springer Wien, New York, 403 p.

Hong C.-K., Kwon J. H., Lee B. M., Lee J., Choi Y. S., Lee S.-B., 2009: Effects of gravity data quality and spacing on accuracy of geoid in South Korea. Earth Planets Space, 61, 7, 927-932, doi : 10.1186/BF03353204.

Huang J., Fotopoulos G., Cheng M. K., Véronneau M., Sideris M. G., 2007: On the estimation of the regional geoid error in Canada. In: Tregoning P., Rizos C. (Eds.): Dynamic planet. International Association of Geodesy Symposia, 130, Springer Berlin, Heidelberg, pp. 272-279, doi : 10.1007/978-3-540-49350-1_41.

Isioye O. A., Youngu T. T., Aledemomi A. S., 2010: Normal gravity and the Nigerian height system. J. Eng. Res. (published by Faculty of Engineering, University of Lagos, Nigeria), 3, 1, 39-49, ISSN: 0795-2333.

Jekeli C., Yang H. J., Kwon J. H., 2009: Using gravity and topography-implied anomalies to assess data requirements for precise geoid computation. J. Geod., 83, 12, 11931202, doi : 10.1007/s00190-009-0337-y.

Jekeli C., 2012: Omission error, data requirements, and the fractal dimension of the geoid. In: Sneeuw N., Novák P., Crespi M., Sansò F., (Eds.): VII Hotine-Marussi Symposium on Mathematical Geodesy. International Association of Geodesy Symposia, 137, Springer-Verlag, Berlin, Heidelberg, Germany, 181-187, doi: 10.1007/978-3 -642-22078-4_27.

Klu M., 2015: Determination of a geoid model for Ghana using the Stokes-Helmert method. MScE thesis, Department of geodesy and geodetic engineering. Technical report No. 298, University of New Brunswick, Canada, 91 p.

Matsuo K., Miyazaki T., Kuroishi Y., 2016: Development of a new gravimetric geoid model for Japan. FIG working week 2016, Recovery from disaster, New Zeeland, May 2-6, 2016, FIG publications.

Novák P., 2000: Evaluation of gravity data for the Stokes Helmert-solution to the geodetic boundary value problem. Technical report number 207 of the Department of geodesy and geodetic engineering, University of New Brunswick. 
Nsombo P., 1996: Geoid determination over Zambia. Unpublished PhD dissertation of Royal Institute of Technology, KTH.

Odumosu J. O., Ajayi O. G., Idowu F. F., Adesina E. A., 2018: Evaluation of the various orthometric height systems and the Nigerian scenario - A case study of Lagos State. J. King Saud Univ. Eng. Sci., 30, 1, 46-53, doi: 10.1016/j.jksues.2015.09.002.

Odumosu J. O., 2019: Determination and Utilization of homogenized gravity dataset for the development of a gravimetric geoid for South Western Zone of Nigeria. A PhD thesis submitted to the School of Postgraduate, Federal University of Technology, Minna, Nigeria.

Ojinnaka O. C., 2007: Principles of Hydrographic Surveying - from Sextant to Satellite. First Edition, ISBN 978-8143-10-5, 317 p.

Oršulić O. B., Markovinović D., Varga M., Bašić T., 2019: The impact of terrestrial gravity data density on geoid accuracy: case study Bilogora in Croatia. Surv. Rev., 52, 373, 299-308, doi: 10.1080/00396265.2018.1562747.

Osazuwa I. B., 1995: An appraisal of the Nigerian gravity standardization net, 1984. Proceedings of the 2nd regional Geodesy and Geophysics Assembly in Africa, 1995.

Sansò F., Sideris M. G., 2013: Geoid determination: Theory and methods. New York, Springer Berlin Heidelberg, doi: 10.1007/978-3-540-74700-0.

Sjöberg L. E., Featherstone W. E., 2004: Two-step procedures for hybrid geoid modelling. J. Geod., 78, 1-2, 66-75, doi : 10.1007/s00190-003-0367-9.

Ulotu P. E., 2009: Geoid model of Tanzania from sparse and varying gravity data density by the KTH method. PhD thesis, Department of Transport and Economics, Division of Geodesy, Royal Institute of Technology (KTH) Stockholm, Sweden.

Wang Y. M., Saleh J., Li X., Roman D. R., 2012: The US Gravimetric Geoid of 2009 (USGG2009): model development and evaluation. Journal of Geodesy 86, 3, 165180, doi : 10.1007/s00190-011-0506-7.

Yahaya S. I., Azzab D. E., 2019: Assessment of recent GOCE-based global geopotential models and EGM2008 in Niger Republic. Geodesy Cartogr., 45, 3, 116-125, doi : 10.3846/gac. 2019.8699. 